\title{
Concentration-dependent differential effects of an epothilone analog on cell cycle and p53 signaling
}

\author{
FAN AN, WEI-JIE ZHAO, LI TANG and RONG-GUO QIU \\ Research Center for Molecular Medicine, Dalian University of Technology, Dalian, Liaoning 116023, P.R. China
}

Received May 12, 2015; Accepted June 22, 2015

DOI: 10.3892/or.2015.4128

\begin{abstract}
The tumor-suppressor protein p53 is considered to be one of the most important transport hubs of cell signal transduction, playing critical roles in the control of cell cycle arrest, apoptosis and many other processes as a nuclear transcription factor. p53 also acts in the cytoplasm to trigger apoptosis. Paclitaxel and other microtubule inhibitors can inhibit the growth of different types of cancer cells and induce apoptosis which is believed to be p53-independent. In the present study, we demonstrated that UTD1, a genetically engineered epothilone analog and a new microtubule inhibitor, activated p53 as a transcription factor at low concentrations demonstrated by its enhanced transcriptional activity and accumulation of p21, which led to cell cycle arrest. However, at high concentrations of UTD1, p53 was accumulated in the cytoplasm which contributed to induction of apoptosis. These observations indicate that the epothilone analog has differential effects on intracellular signaling and implies that p53 plays different roles in cells exposed to different concentrations of the anticancer agent.
\end{abstract}

\section{Introduction}

The epothilones are macrolide compounds originally isolated from a culture broth of the myxobacterium Sorangium cellulosum in 1987 (1). The epothilones have strong antitumor activities against human types of cancers (2) with a similar mode of action as the taxanes. Although both epothilones and taxanes are microtubule stabilizers, the epothilones have significant antitumor activities against taxane-resistant human cancers (3-7). This characteristic makes epothilones a hotspot for development of novel cancer therapeutics and brings hope for the patients who are refractory to taxane treatment (8-11). Ixabepilone (aza-epothilone B; Ixempra ${ }^{\circledR}$; Bristol-Myers

Correspondence to: Professor Rong-Guo Qiu or Dr Li Tang, Research Center for Molecular Medicine, Dalian University of Technology, Dalian, Liaoning 116023, P.R. China

E-mail: rqiu2001@yahoo.com

E-mail: tangli63b@yahoo.com

Key words: p53, epothilone, apoptosis, cellular localization, cell cycle arrest
Squibb, Princeton, NJ, USA) has been evaluated in clinical trials (12-19) and was approved by the FDA to treat metastatic and advanced breast cancers that are refractory to other types of chemotherapy (20).

UTD1 is an epothilone analog generated by genetic engineering of the epothilone biosynthetic gene cluster. UTD1 has demonstrated high activities in vitro and in vivo against a broad range of tumors, including paclitaxel-sensitive tumors as well as paclitaxel-resistant human carcinoma models (Qiu et al, unpublished data). UTD1 is now under clinical investigation (21). However, the effect of UTD1 on important intracellular signaling pathways related to its anticancer mechanism remains to be addressed.

p53 protein is a well known tumor suppressor that coordinates cellular signals to mediate cell cycle arrest, apoptosis and differentiation (22), and plays critical roles in cancer development (23). p53 keeps its basic level under normal conditions due to the p53/MDM2-negative feedback control. When cancer develops, the post-transcriptional modification of p53 is induced, which keeps p53 away from ubiquitination by MDM2 and leads to its accumulation in the cells.

p53 plays two quite different roles at different cellular localizations: as a transcription factor in the nucleus and as a pro-apoptotic protein in the cytoplasm, respectively. As a transcription factor, p53 binds to DNA and induces transcription of downstream molecules in response to several stress signals, such as growth arrest, apoptosis, senescence and DNA repair (24). The post-transcriptional modification of p53, by ATM (ATR), CHK2 (CHK1), cell cycle checkpoint and other upstream proteins, directly controls its DNA binding and transcriptional activities. Both $p 21$ and bax are target genes of p53, and it is generally considered that $\mathrm{p} 21$ and Bax are markers of p53-induced cell cycle arrest and apoptosis (25-27). In addition to its transcriptional activity, p53 also acts as a BH3-only protein that moves to the mitochondria, and contributes to the mitochondrial outer membrane permeabilization (MOMP) by protein-protein interaction with $\mathrm{Bcl} 2$ family members (28-31), and then induces the release of cytochrome $c$ from mitochondria to trigger apoptosis.

It has been previously demonstrated that Taxol treatment led to accumulation of p53 in a series of cancer cell lines. However, the pro- or anti-apoptotic role of p53 in microtubule inhibitor-induced cell death has been debatable to date, or whether mitotic blockage triggers a p53-independent apoptotic pathway (32-34). 
In the present study, we investigated the role of p53 in the UTD1-induced cell death in the MCF-7 cell line which expresses wild-type p53 and the HT29 cell line which expresses mutant p53. We found that HT29 cells were more resistant to UTD1-induced cell death than MCF-7 cells. UTD1 induced aneuploid cells in the MCF-7 and HT29 cell lines at low concentrations, and induced $\mathrm{G}_{2}-\mathrm{M}$ cell cycle arrest at high concentrations. Our results demonstrated that p53 was localized to different cellular sites and played distinct roles in these two effects of the epothilone analog. Its transcriptional activity was activated in induction of aneuploid cells, and its protein level was accumulated and enriched in the cytoplasm to cause $\mathrm{G}_{2}-\mathrm{M}$ cell cycle arrest.

\section{Materials and methods}

Compound. UTD1 was provided by Biostar Technologies, Ltd. (Beijing, China). UTD1 is an epothilone derivative generated by genetic manipulation of the epothilone biosynthetic gene cluster. It is now under phase III clinical trials.

Cell culture. MCF-7 and HT29 cells were cultured in Dulbecco's modified Eagle's medium (DMEM) (HyClone, Logan, UT, USA), supplemented with $10 \%$ fetal bovine serum (Gibco, Grand Island, NY, USA), in a $5 \% \mathrm{CO}_{2}$ humidified atmosphere at $37^{\circ} \mathrm{C}$. Phosphate-buffered saline (PBS) containing $0.25 \%$ trypsin and $0.02 \%$ EDTA (Sigma, St. Louis, MO, USA) was used to harvest the cells. For various tests, $3 \times 10^{3}, 3 \times 10^{4}$ and $1.2 \times 10^{6}$ cells were cultured in 96-, 24- and 6 -well plates with drug-free medium, respectively. After $24 \mathrm{~h}$, the cells were treated with various concentrations of UTD1. In all the experiments, cells were treated with UTD1 at the indicated concentrations and times, starting from a stock solution of $100 \mu \mathrm{mol} / 1$ in dimethylsulfoxide (DMSO) (Sigma).

Flow cytometry. The cells treated with various concentrations of UTD1 for 24 or $48 \mathrm{~h}$ were collected and washed twice, and then fixed with $70 \%$ ethanol at $-20^{\circ} \mathrm{C}$ overnight. The cells were rehydrated in PBS and re-suspended in PBS containing $100 \mu \mathrm{g} / \mathrm{ml}$ RNase (Sigma) and $10 \mu \mathrm{g} / \mathrm{ml}$ propidium iodide. The cells were analyzed by flow cytometry with a FACScan (Becton-Dickinson Biosciences, San Jose, CA, USA). Data were analyzed with ModFit LT software.

Immunoblotting. The cells treated with various concentrations of UTD1 for 24 or $48 \mathrm{~h}$ were lysed in RIPA buffer containing a proteinase inhibitor. The protein extract $(30 \mu \mathrm{g})$ from each sample, as determined by BCA protein assay (Thermo Fisher Scientific, USA), was heated with loading buffer for $5 \mathrm{~min}$ at $95^{\circ} \mathrm{C}$, and then electrophoresed through a $12 \%$ polyacrylamide-SDS gel and electroblotted onto nitrocellulose membranes in transfer buffer $(50 \mathrm{mM}$ Tris, $100 \mathrm{mM}$ glycine and $20 \%$ methanol) for $2 \mathrm{~h}$ at $100 \mathrm{~V}$. The following antibodies were used in the immunoblot analysis: anti- $\beta$-tubulin, antip53 (DO-1), anti-p21 (F-5) (from Santa Cruz Biotechnology); anti-caspase 7 (M45) and anti-Bax (C62) (from Bioworld Technology Biotechnology, USA).

Immunofluorescence. The cells were plated onto glass coverslips in 6-well plates. The next day, the cells were treated with UTD1 for $24 \mathrm{~h}$, and then washed with PBS and fixed with $3 \%$ paraformaldehyde for $30 \mathrm{~min}$ at room temperature. The coverslips were then washed with PBS and blocked by PBS containing $1 \%$ BSA and $0.3 \%$ Triton for $1 \mathrm{~h}$. The cells were then dyed using Hoechst 33258 (Sigma) and MitoTracker Red CMXRos (Invitrogen, USA) for $30 \mathrm{~min}$ and incubated with anti-p53 antibody (Alexa Fluor 488 conjugate; Cell Signaling).

Transcriptional activity analysis. PathDetect ${ }^{\circledR}$ In Vivo Signal Transduction Pathway cis-Reporting Systems containing p53-Luc, pAP-1-Luc and pNF- $\mathrm{B}$-Luc were purchased from Stratagene (USA). Lipofectamine ${ }^{\mathrm{TM}} 2000$ was from Invitrogen, and Dual-Glo ${ }^{\circledR}$ Luciferase Assay System and pRL-TK were from Promega (USA). Experiments were performed according to the manufacturer's protocols.

Proliferation analysis. The cells were treated with various concentrations of UTD1 for 48 and $72 \mathrm{~h}$, and then proliferation was evaluated by an MTT (Sigma) assay. $\mathrm{IC}_{50}$ values were then calculated.

\section{Results}

UTD1 inhibits the growth of MCF-7 and HT29 cells and is a strong promoter of tubulin polymerization. The inhibitory effects of UTD1 on proliferation of the wild-type and mutant p53 cell lines and tubulin polymerization were investigated. Breast cancer cell line MCF-7 and colon cancer cell line HT29 were treated with various concentrations of UTD1 for 48 and $72 \mathrm{~h}$, respectively. As shown in Fig. 1 , the $\mathrm{IC}_{50}$ values for the cytotoxicity of UTD1 on MCF-7 (Fig. 1A) and HT29 cells (Fig. 1B) were 390 and $525 \mathrm{nM}$ at $48 \mathrm{~h}, 51$ and $187 \mathrm{nM}$ at $72 \mathrm{~h}$, indicating a strong growth inhibitory activity towards human cancer cells for UTD1; and cells with wild-type p53 were more sensitive. Therefore, we chose $50 \mathrm{nM}$ ( $\mathrm{IC}_{50}$ for MCF-7), $200 \mathrm{nM}\left(\mathrm{IC}_{50}\right.$ for HT29) and $800 \mathrm{nM}$ (>90\% inhibition for both cell lines) of UTD1 in the subsequent experiments. We also confirmed that UTD1 promoted tubulin polymerization and enhanced microtubule stability in vitro similar to other epothilones, as shown by a decrease in soluble tubulin and an increase in polymerized tubulin in the UTD1-treated cells (Fig. 2).

UTD1 transforms MCF-7 and HT29 cells into aneuploid cells and induces $G_{2}-M$ cell cycle arrest at different concentrations. In analyzing UTD1-treated MCF-7 and HT29 cells by flow cytometry, we observed that both cancer cell lines were transformed into aneuploid cells after treatment with $50 \mathrm{nM}$ of UTD1 for $24 \mathrm{~h}$, and were blocked at $\mathrm{G}_{2} / \mathrm{M}$ of the cell cycle at higher concentrations of UTD1 (Fig. 3). This observation demonstrated a concentration-dependent differential effect of UTD1 on the cell cycle of cancer cells. This may have been due to abnormal microtubule dynamics, the fact that cells treated with low concentrations of UTD1 suffered mitotic disorder, and chromosomes were randomly distributed to daughter cells which became aneuploid cells. However, higher concentrations of UTD1 arrested cells at $\mathrm{G}_{2} / \mathrm{M}$, preventing mitotic progression.

UTD1 induces apoptosis at high but not low concentrations. To assess whether the epothilone analog induces apoptosis, cancer 

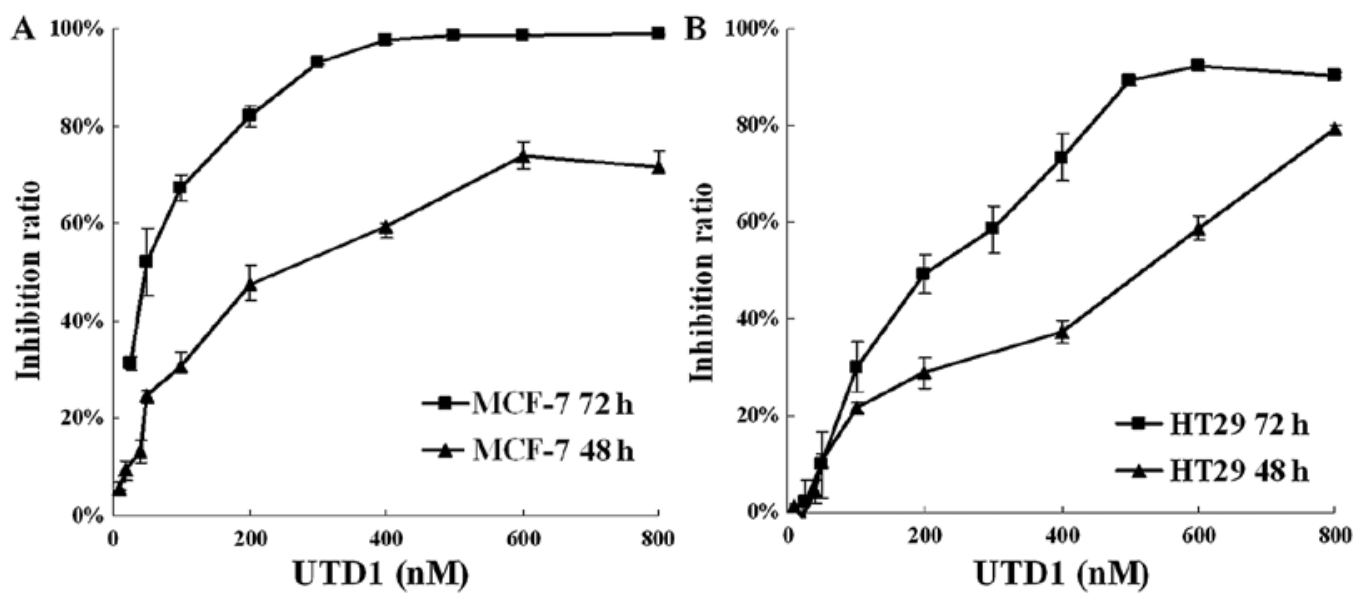

Figure 1. UTD1 inhibits cancer cell proliferation. The effect of UTD1 on the proliferation of MCF-7 and HT29 cells was examined using the MTT assay as described in 'Materials and methods'. (A) MCF-7 and (B) HT29 cells were exposed to 10-800 nM of UTD1 for 48 and $72 \mathrm{~h}$.

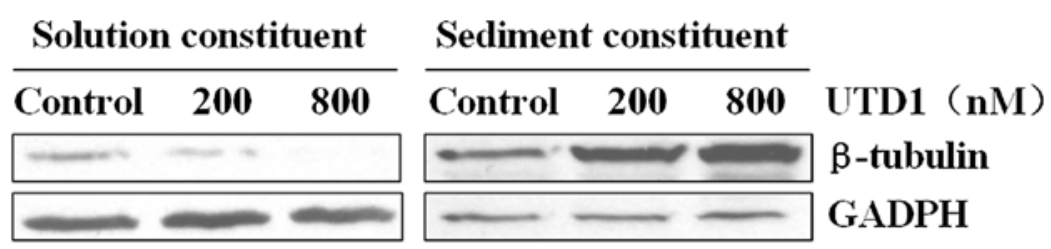

Figure 2. UTD1 promotes tubulin polymerization in the MCF-7 cells. MCF-7 cells were exposed to 200 and $800 \mathrm{nM}$ of UTD1 for $4 \mathrm{~h}$ respectively, and then tubulin in solution and polymerized tubulin in sediment constituents were analyzed by western blotting.

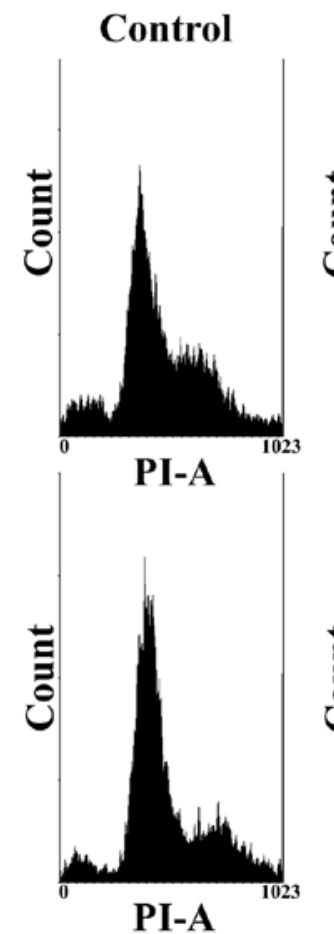

PI-A
50
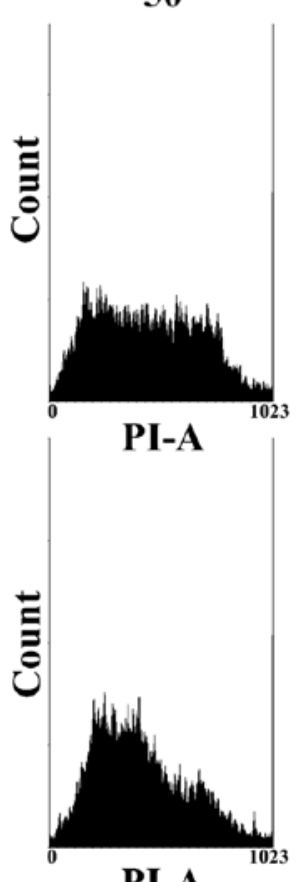

200
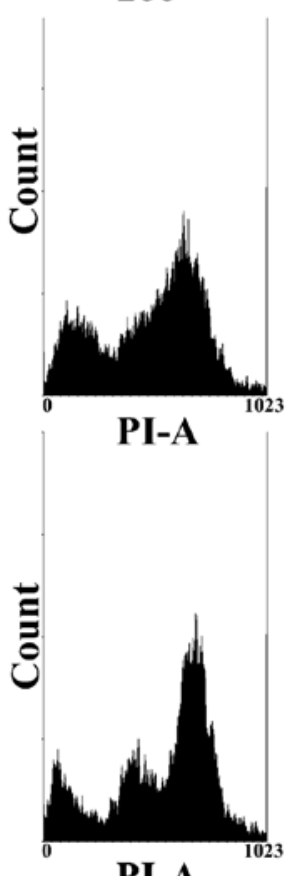

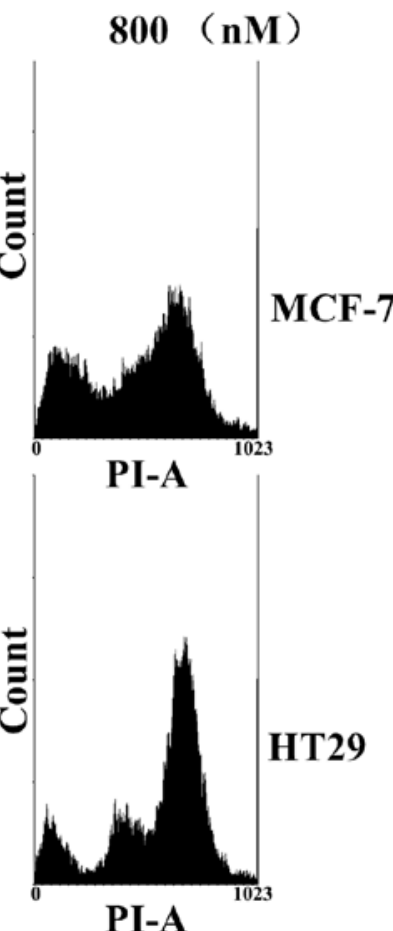

Figure 3. Effects of different concentrations of UTD1 on the cell cycle. Cells were treated for $24 \mathrm{~h}$ with UTD1 at the indicated concentrations. After treatments, the cells were collected and fixed, and subsequently analyzed by flow cytometry.

cells were treated with different concentrations of UTD1 and apoptotic markers were analyzed. As shown in Fig. 4, caspase 7 zymogen was degraded in both the MCF-7 and HT29 cells exposed to $800 \mathrm{nM}$, yet not at $50 \mathrm{nM}$ of UTD1. In addition, activated caspase 7 subunit was detected in the MCF-7 cells. This observation suggests that high concentrations of UTD1 induce 

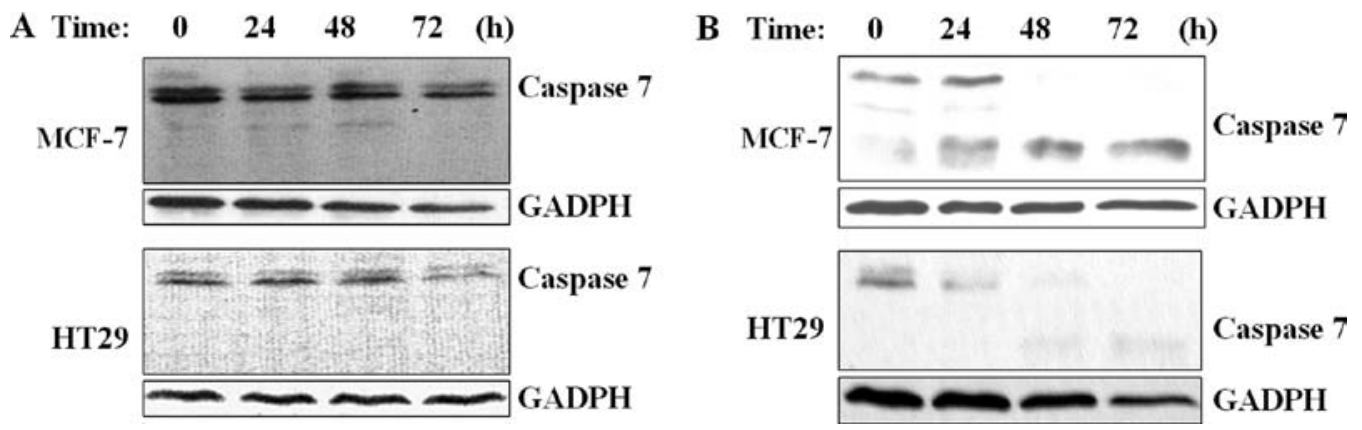

Figure 4. UTD1 induces apoptosis at a high but not a low concentration. Both MCF-7 and HT29 cells were exposed to (A) 50 and (B) $800 \mathrm{nM}$ UTD1, and the caspase 7 level was assessed by western blotting at the indicated time points. GADPH was used as a loading control.

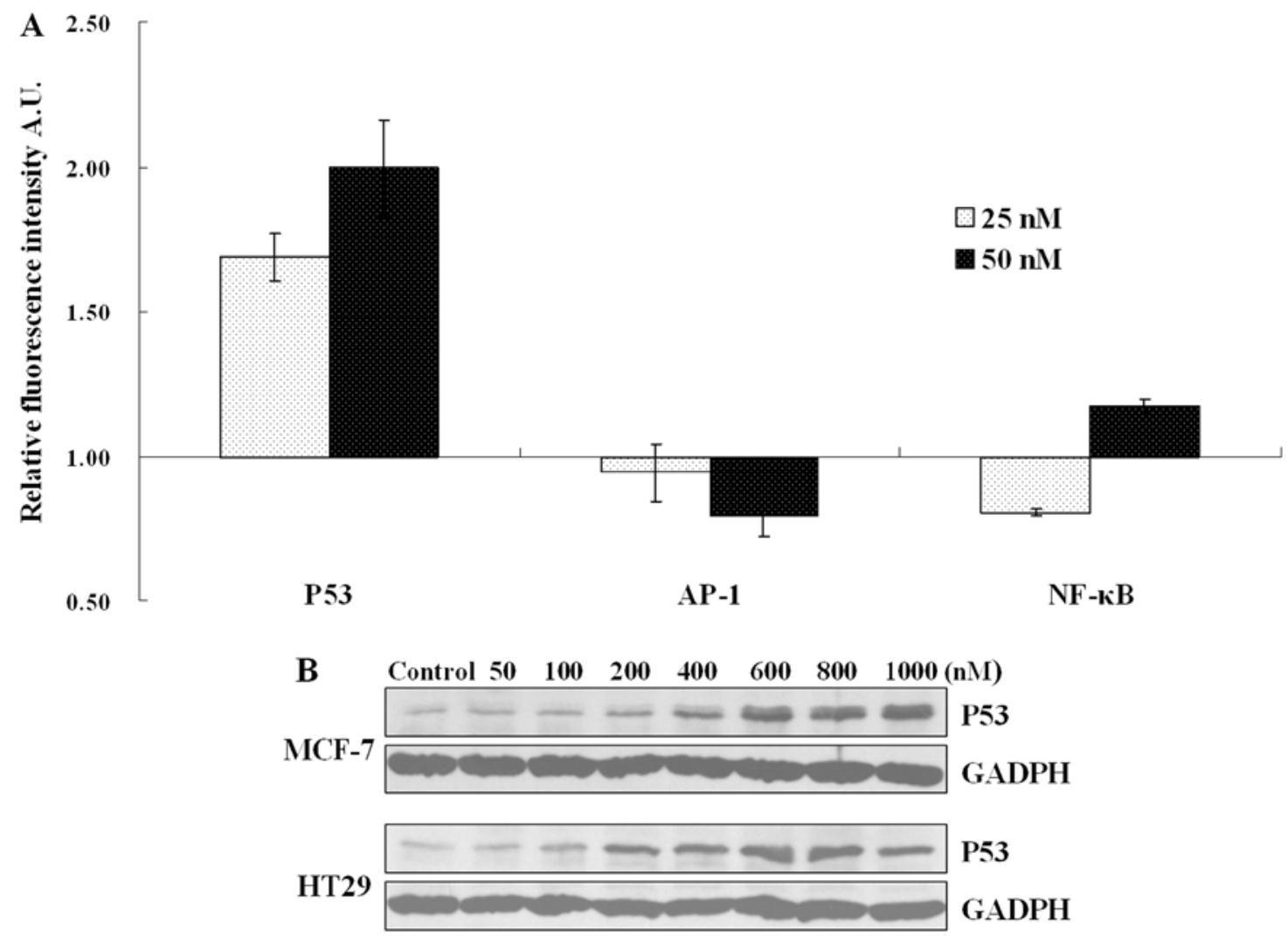

Figure 5. Differential effects of various UTD1 concentrations on the transcriptional activity and protein level of p53. (A) p53 transcriptional activity was activated by a low concentration of UTD1. MCF-7 cells were transfected with pAP1-luc, p53-luc and pNF-kB-luc respectively, with pRL-TK as an internal reference. Then cells were exposed to UTD1 for $24 \mathrm{~h}$ at different concentrations. Relative fluorescence intensity was calculated using the ratio of luc to pRLTK, and the results were calculated using the ratio of dosing relative to fluorescence intensity. (B) Protein quantity of p53 in both the MCF-7 and HT29 cells accumulated after treatment with high concentrations of UTD1. Both MCF-7 and HT29 cells were exposed to different concentrations of UTD1 for 24 h, and then cell lysates were prepared and p53 protein was assessed by western blotting. GADPH was used as a loading control.

apoptosis in MCF-7 cells but not in the case of low concentrations (Fig. 4). Cells may survive at low concentrations of UTD1, but undergo mitotic disorder.

p53 transcriptional activity is activated at low concentrations and accumulated at high concentrations of UTD1. To investigate a possible effect of UTD1 on transcriptional activity of p53 and various other factors important for cell apoptosis and survival control, reporter gene assays of p53, AP-1 and NF- $\mathrm{B}$ were carried out. Due to the low transfection efficiency of the HT29 cells, only MCF-7 cells were used in this experiment. As shown in Fig. 5A, after treatment with low concentrations of UTD1 for $24 \mathrm{~h}$, p53-induced luc fluorescence intensity was markedly increased. By contrast, AP-1- and NF- $\kappa \mathrm{B}$-induced luc fluorescence intensities were nearly unchanged. We then further investigated the protein quantity of p53 in both cell lines treated with UTD1. p53 tended to accumulate in the UTD1 cells treated with high concentrations, yet not in the cells treated with low concentrations (Fig. 5B).

p53 plays an anti-apoptotic role in the cells treated with low concentrations of UTD1. To clarify the contradiction of the pro- or anti-apoptotic role of p53 in UTD1-treated cells, the expression levels of p21 and Bax in these cells were 
MCF-7

HT29

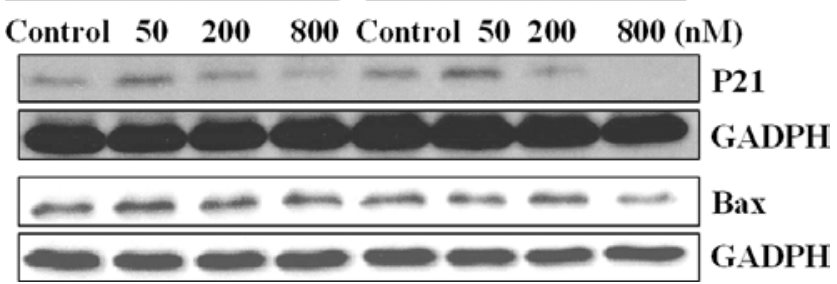

Figure 6. p21 was expressed at low concentrations of UTD1, while Bax was not expressed under all the conditions. MCF-7 and HT29 cells were exposed to different concentrations of UTD1 for $24 \mathrm{~h}$, then harvested and p21 and Bax were assessed by western blotting. GADPH was used as a loading control.
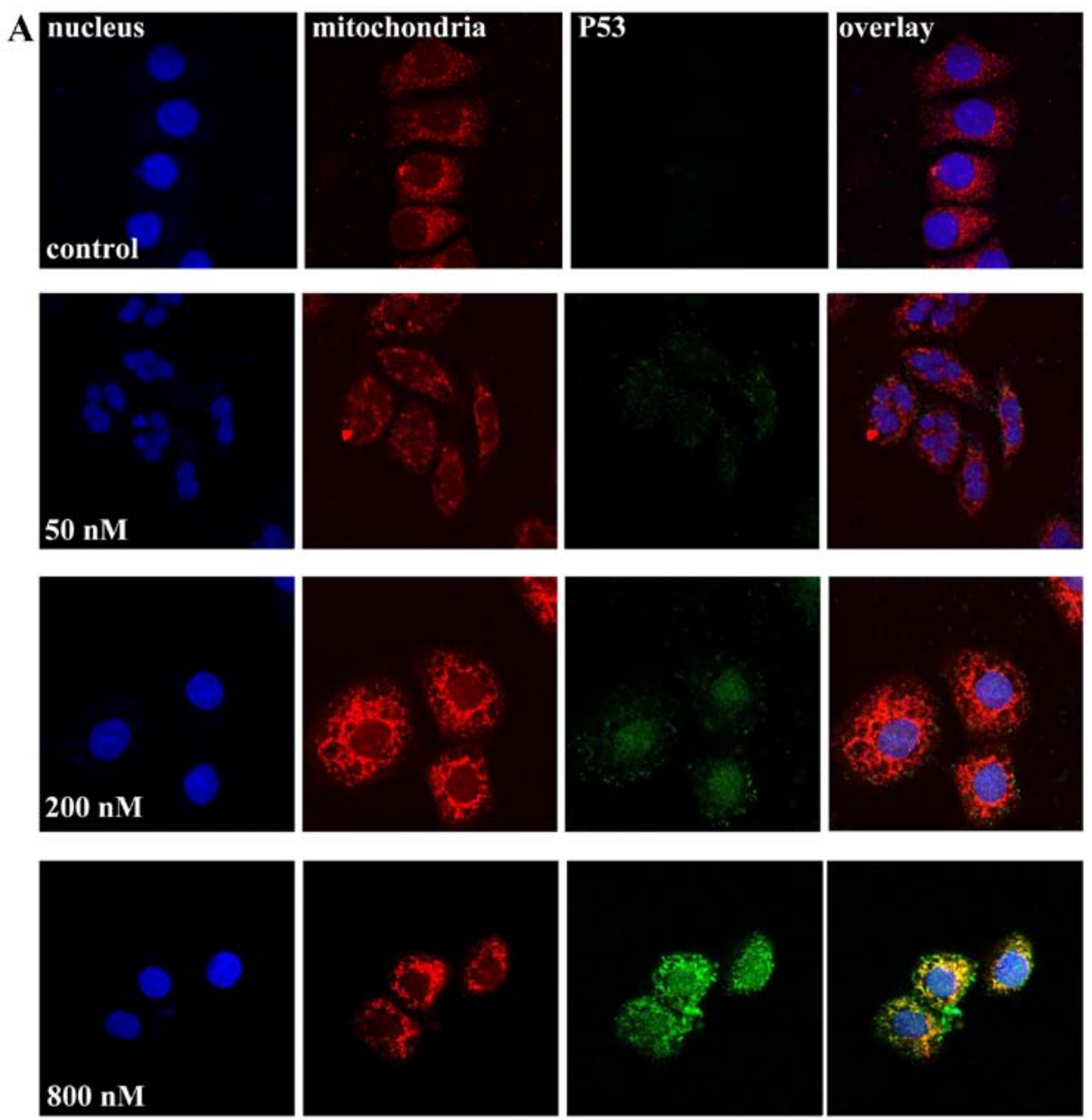

Figure 7. Localization of p53 in the MCF-7 cells treated with different concentrations of UTD1. (A) MCF-7 cells were exposed to different concentrations of UDT1 for $24 \mathrm{~h}$ and stained with Hoechst 33258 and MitoTracker Red CMXRos. p53 protein was visualized by immunofluorescence using an anti-p53 antibody.

investigated (Fig. 6), as the downstream proteins of p53, p21 and Bax are considered to be the hallmarks of p53 transcription-dependent activity on cell cycle arrest and apoptosis, respectively (21). As shown in Fig. 6, p21 was expressed at a low concentration of UTD1, and the protein quantity of Bax was unchanged at both concentrations. This suggests that a low concentration of UTD1 induced abnormal mitosis resulting in activation of $\mathrm{p} 21$, which in turn blocked the cell cycle at $\mathrm{G}_{2} / \mathrm{M}$. As the transcription factor of p21, p53 appears to play an antiapoptotic role in this process. A high concentration of UTD1 resulted in the accumulation of p53, while the level of down- stream pro-apoptosis protein Bax was not affected, suggesting that apoptosis induction was p53 transcription-independent or this effect was Bax-independent.

p53 protein is enriched in the cytoplasm of the cells exposed to a high concentration of UTD1. To explain the contradiction between the high protein accumulation and low transcriptional activity of p53 in cells treated with a high concentration of UTD1, we tracked the localization of p53 by the anti-p53 fluorescent antibody. Hoechst 33258 and MitoTracker Red CMXRos were used to mark the nuclei and mitochondria, 

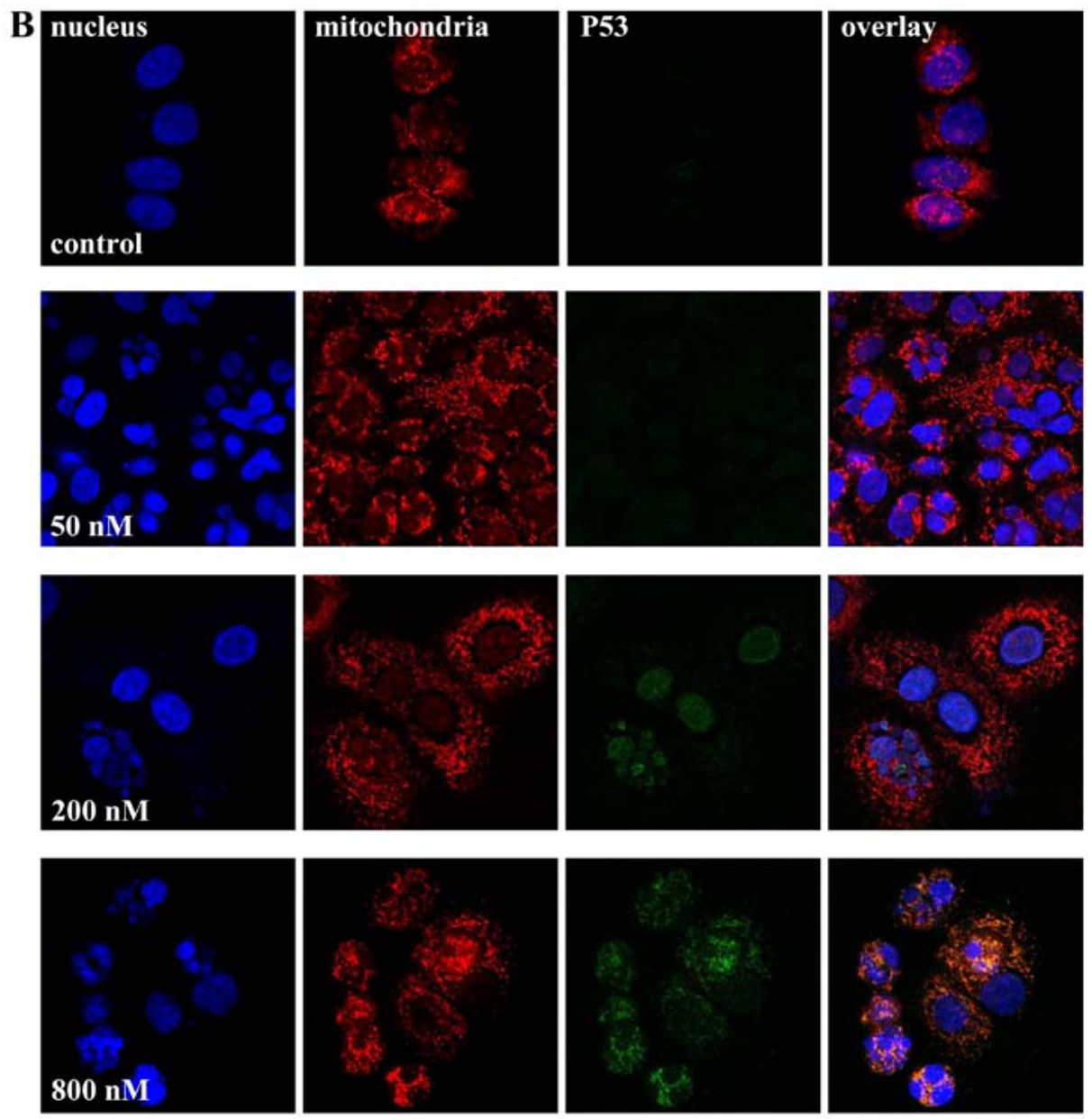

Figure 7. Continued. Localization of p53 in the HT29 cells treated with different concentrations of UTD1. (B) HT29 cells were exposed to different concentrations of UDT1 for $24 \mathrm{~h}$ and stained with Hoechst 33258 and MitoTracker Red CMXRos. p53 protein was visualized by immunofluorescence using an anti-p53 antibody.

respectively. As shown in Fig. 7, both MCF-7 and HT29 cells were transformed into aneuploid cells following treatment with a low concentration of UTD1, with their nucleolus dividing into unequal sizes quite different from the apoptotic cells. p53 in the control and low dosage-treated cells was hardly detectable. These observations were consistent with the results of the flow cytometric and western blot analyses. Following treament of 200 nM UTD1, p53 was detectable, locating in the nucleolus. However, when the concentration of UTD1 was increased to $800 \mathrm{nM}$, most p53 was detected in the cytoplasm. These observations indicate that the cellular localization of p53 is affected by the concentration of UTD1, which in turn influences the function of this important tumor-suppressor protein.

\section{Discussion}

Epothilones have been widely used in the clinical development of therapies for diverse types of cancer, yet the mechanism underlying their antitumor activities, such as apoptosis induction is not yet fully understood. p53 is well known as a tumor-suppressor, controlling DNA repair, cell cycle arrest and apoptosis in a transcriptional-dependent or transcriptionalindependent way, and accumulates in the cells treated with Taxol. However, inactivation experiments of p53 demonstrated that the apoptosis induced by Taxol is p53-independent (35). However, the role of p53 in other microtubule inhibitorinduced cell death remains unclear.

In the present study, we studied the effect of UTD1, a genetically engineered epothilone analog, on p53 and its downstream proteins in MCF-7 and HT29 cells. The $\mathrm{IC}_{50}$ values of UTD1 on MCF-7 and HT29 cells were 390 and $525 \mathrm{nM}$ at $48 \mathrm{~h}, 51$ and $187 \mathrm{nM}$ at $72 \mathrm{~h}$, respectively. Notably, different concentrations of UTD1 led both types of cells to different fates. When exposed to a low concentration $(50 \mathrm{nM})$ of UTD1 for $24 \mathrm{~h}$, both types of cells were transformed into aneuploid cells with their nucleolus dividing into unequal sizes. The protein level of p53 was not significantly changed as demonstrated by western blot and confocal microscopy analyses. However, the transcriptional activity of p53 in the MCF-7 cells was markedly increased. By contrast, the transcriptional activities of AP-1 and $\mathrm{NF}-\kappa \mathrm{B}$ were not affected. The effect on $\mathrm{p} 53$ transcription could be supported by the increased protein level of $\mathrm{p} 21$. When the concentration of UTD1 was increased to $200 \mathrm{nM}$, results of the flow cytometry showed that most MCF-7 and HT29 cells were blocked at $\mathrm{G}_{2} / \mathrm{M}$ of the cell cycle at the $24-\mathrm{h}$ point, at which the protein level of p53 was upregulated and mainly located in the nucleus. Yet, upregulated p53 did not result in an increase 
in the protein levels of p21 and Bax. Similarly, treatment with $800 \mathrm{nM}$ UTD1 for $24 \mathrm{~h}$ led both types of cells to be blocked at the $\mathrm{G}_{2} / \mathrm{M}$ phase of the cell cycle and neither p21 nor Bax was increased when compared with the control. Notably, p53 was located in the cytoplasm, yet not in the nucleus which was quite different from the low-concentration conditions and control cells.

We speculated that p53 functions as an anti-apoptotic transcription factor at a low concentration of UTD1 and as a pro-apoptotic protein at a high concentration of UTD1.

At the low concentration, $50 \mathrm{nM}$ UTD1 disturbed mitosis, yet did not block it completely, thus it transformed MCF-7 and HT29 cells into aneuploid cells and activated the G0/ G1 checkpoint and p53. Accumulation of protein is not necessary for the transcriptional activity of p53, and a basal level of p53 is sufficient for that. Subsequently p21, but not Bax is transcribed.

At a high concentration, microtubule dynamics were totally destroyed and mitosis was completely blocked. We found that p21 and Bax were not upregulated, and p53 was localized mainly in the cytoplasm, probably at mitochondria. These findings indicate that p53 accumulation in the cytoplasm functions as a pro-apoptotic protein to induce the release of cytochrome $c$ from mitochondria.

A disorder in mitosis activates more than one signaling pathways and leads to cell death. This may explain why cells containing mutant p53 or no p53 can still be blocked at the $\mathrm{G}_{2}$ phase of the cell cycle rigidly by microtubule inhibitors and undergo cell death. We also found that MCF-7 cells were completely inhibited by high concentrations $(>500 \mathrm{nM})$ of UTD1. The inhibition rate at $72 \mathrm{~h}$ was above $99 \%$ (Fig. 1A); however, HT29 cells seemed to be more resistant to this drug treatment with the inhibition rate never higher than $90 \%$ (Fig. 1B). Another significant distinction is that we did not detect activated caspase 7 in the cells treated with $800 \mathrm{nM}$ UTD1, suggesting that high concentrations of UTD1 fail to induce apoptosis in HT29 cells. This differential effect reflects the difference in p53 status in these two cancer cell lines.

\section{Acknowledgements}

We thank Dr Jinsong Yan of the Dalian Medical University for advice and expertise with the luminescence microplate readers.

\section{References}

1. Gerth K, Bedorf N, Höfle G, Irschik H and Reichenbach H: Epothilons A and B: Antifungal and cytotoxic compounds from Sorangium cellulosum (Myxobacteria). Production, physicochemical and biological properties. J Antibiot 49: 560-563, 1996.

2. Goodin S, Kane MP and Rubin EH: Epothilones: Mechanism of action and biologic activity. J Clin Oncol 22: 2015-2025, 2004.

3. Lee JJ and Swain SM: Development of novel chemotherapeutic agents to evade the mechanisms of multidrug resistance (MDR) Semin Oncol 32 (Suppl 7): S22-S26, 2005.

4. Lee FY, Borzilleri R, Fairchild CR, Kim SH, Long BH, Reventos-Suarez C, Vite GD, Rose WC and Kramer RA: BMS-247550: A novel epothilone analog with a mode of action similar to paclitaxel but possessing superior antitumor efficacy. Clin Cancer Res 7: 1429-1437, 2001.

5. Fojo AT and Menefee M: Microtubule targeting agents: Basic mechanisms of multidrug resistance (MDR). Semin Oncol 32 (Suppl 7): S3-S8, 2005.
6. Orr GA, Verdier-Pinard P, McDaid $\mathrm{H}$ and Horwitz SB: Mechanisms of Taxol resistance related to microtubules. Oncogene 22: 7280-7295, 2003.

7. Bhandari MS and Hussain M: Epothilones and the next generation of phase III trials for prostate cancer. BJU Int 96: 296-302, 2005.

8. Lee JJ and Swain SM: The epothilones: Translating from the laboratory to the clinic. Clin Cancer Res 14: 1618-1624, 2008.

9. Bergstralh DT and Ting JP: Microtubule stabilizing agents: Their molecular signaling consequences and the potential for enhancement by drug combination. Cancer Treat Rev 32: 166-179, 2006.

10. Larkin JM and Kaye SB: Epothilones in the treatment of cancer. Expert Opin Investig Drugs 15: 691-702, 2006.

11. Cortes J and Baselga J: Targeting the microtubules in breast cancer beyond taxanes: The epothilones. Oncologist 12: 271-280, 2007.

12. Low JA, Wedam SB, Lee JJ, Berman AW, Brufsky A, Yang SX, Poruchynsky MS, Steinberg SM, Mannan N, Fojo T, et al: Phase II clinical trial of ixabepilone (BMS-247550), an epothilone $\mathrm{B}$ analog, in metastatic and locally advanced breast cancer. J Clin Oncol 23: 2726-2734, 2005.

13. Thomas E, Tabernero J, Fornier M, Conté P, Fumoleau P, Lluch A, Vahdat LT, Bunnell CA, Burris HA, Viens P, et al: Phase II clinical trial of ixabepilone (BMS-247550), an epothilone B analog, in patients with taxane-resistant metastatic breast cancer. J Clin Oncol 25: 3399-3406, 2007.

14. Perez EA, Lerzo G, Pivot X, Thomas E, Vahdat L, Bosserman L, Viens P, Cai C, Mullaney B, Peck R, et al: Efficacy and safety of ixabepilone (BMS-247550) in a phase II study of patients with advanced breast cancer resistant to an anthracycline, a taxane, and capecitabine. J Clin Oncol 25: 3407-3414, 2007.

15. Roché H, Yelle L, Cognetti F, Mauriac L, Bunnell C, Sparano J, Kerbrat P, Delord JP, Vahdat L, Peck R, et al: Phase II clinical trial of ixabepilone (BMS-247550), an epothilone B analog, as first-line therapy in patients with metastatic breast cancer previously treated with anthracycline chemotherapy. J Clin Oncol 25: 3415-3420, 2007.

16. Denduluri N, Low JA, Lee JJ, Berman AW, Walshe JM, Vatas U, Chow CK, Steinberg SM, Yang SX and Swain SM: Phase II trial of ixabepilone, an epothilone B analog, in patients with metastatic breast cancer previously untreated with taxanes. J Clin Oncol 25: 3421-3427, 2007.

17. Vahdat LT, Thomas E, Li R, et al: Phase III trial of ixabepilone plus capecitabine compared to capecitabine alone in patients withmetastatic breast cancer (MBC) previously treated or resistant to an anthracycline and resistant to taxanes. Proc Am Soc Clin Oncol 25: 1006, 2007.

18. Denduluri N, Lee JJ, Walshe J, Berman AW, Vatas U, Chow CK, Steinberg SM, Cox MC, Low JA and Swain SM: Phase II trial of ixabepilone, an epothilone B analog, given daily for three days every three weeks, in metastatic breast cancer. Invest New Drugs 25: 63-67, 2007.

19. Lee JJ, Low JA, Croarkin E, Parks R, Berman AW, Mannan N, Steinberg SM and Swain SM: Changes in neurologic function tests may predict neurotoxicity caused by ixabepilone. J Clin Oncol 24: 2084-2091, 2006.

20. Winer E, Gralow J, Diller L, Karlan B, Loehrer P, Pierce L, Demetri G, Ganz P, Kramer B, Kris M, et al: Clinical cancer advances 2008: Major research advances in cancer treatment, prevention, and screening - a report from the American Society of Clinical Oncology. J Clin Oncol 27: 812-826, 2009.

21. Zhang P, Sun M, Qiu R, Tang L, Dou G and Xu B: Phase I clinical and pharmacokinetic study of UTD1, a genetically engineered epothilone analog in patients with advanced solid tumors. Cancer Chemother Pharmacol 68: 971-978, 2011.

22. Vousden KH and Lane DP: p53 in health and disease. Nat Rev Mol Cell Biol 8: 275-283, 2007.

23. Puca R, Nardinocchi L, Givol D and D'Orazi G: Regulation of p53 activity by HIPK2: Molecular mechanisms and therapeutical implications in human cancer cells. Oncogene 29: 4378-4387, 2010.

24. Vazquez A, Bond EE, Levine AJ and Bond GL: The genetics of the p53 pathway, apoptosis and cancer therapy. Nat Rev Drug Discov 7: 979-987, 2008.

25. Chen JG, Yang CP, Cammer M and Horwitz SB: Gene expression and mitotic exit induced by microtubule-stabilizing drugs. Cancer Res 63: 7891-7899, 2003.

26. Blagosklonny MV: Prolonged mitosis versus tetraploid checkpoint: How p53 measures the duration of mitosis. Cell Cycle 5: 971-975, 2006. 
27. Blagosklonny MV: Mitotic arrest and cell fate: Why and how mitotic inhibition of transcription drives mutually exclusive events. Cell Cycle 6: 70-74, 2007.

28. Marchenko ND, Wolff S, Erster S, Becker K and Moll UM: Monoubiquitylation promotes mitochondrial p53 translocation. EMBO J 26: 923-934, 2007.

29. Moll UM, Marchenko N and Zhang XK: p53 and Nur77/TR3 - transcription factors that directly target mitochondria for cell death induction. Oncogene 25: 4725-4743, 2006.

30. Tomita Y, Marchenko N, Erster S, Nemajerova A, Dehner A, Klein C, Pan H, Kessler H, Pancoska P and Moll UM: WT p53, but not tumor-derived mutants, bind to $\mathrm{Bcl} 2$ via the DNA binding domain and induce mitochondrial permeabilization. J Biol Chem 281: 8600-8606, 2006.

31. Leu JI, Dumont P, Hafey M, Murphy ME and George DL: Mitochondrial p53 activates Bak and causes disruption of a Bak-Mcll complex. Nat Cell Biol 6: 443-450, 2004.
32. Bacus SS, Gudkov AV, Lowe M, Lyass L, Yung Y, Komarov AP, Keyomarsi K, Yarden Y and Seger R: Taxol-induced apoptosis depends on MAP kinase pathways (ERK and p38) and is independent of p53. Oncogene 20: 147-155, 2001.

33. Woods CM, Zhu J, McQueney PA, Bollag D and Lazarides E: Taxol-induced mitotic block triggers rapid onset of a p53-independent apoptotic pathway. Mol Med 1: 506-526, 1995.

34. Giannakakou P, Robey R, Fojo T and Blagosklonny MV: Low concentrations of paclitaxel induce cell type-dependent $\mathrm{p} 53$, p21 and G1/G2 arrest instead of mitotic arrest: Molecular determinants of paclitaxel-induced cytotoxicity. Oncogene 20: 3806-3813, 2001.

35. Lanni JS, Lowe SW, Licitra EJ, Liu JO and Jacks T: p53-independent apoptosis induced by paclitaxel through an indirect mechanism. Proc Natl Acad Sci USA 94: 9679-9683, 1997. 